\title{
PROCESSOS AUTÔNOMOS E DE ENVOLVIMENTOS NA
} AMAZÔNIA BRASILEIRA: A ETNOGÊNESE DOS POVOS NA TERRA INDÍGENA MARÓ

\section{AUTONOMOUS AND INVOLVEMENT PROCESSES IN THE BRAZILIAN AMAZON: PEOPLE'S ETHNOGENESIS ON THE MARÓ INDIGENOUS LAND}

Bárbara Dias ${ }^{22}$

Dernival Venâncio Ramos Júnior ${ }^{23}$

\begin{abstract}
The article analyzes the re-involvements, protagonism and identity dynamics of the peoples of the Maró Indigenous Lands, in the Tapajós valley (Pará, in the Brazilian Amazon). Unveiling its historical trajectory, marked by the struggle in territorial demarcation and the constant threat of projects of "progress and development", reflections are produced that demonstrate the complexity of the reactions, integrating the political doing with the force of their knowledge and know-how.
\end{abstract}

\section{RESUMO}

No artigo são analisados os re-envolvimentos, o protagonismo e a dinâmica identitária dos povos das Terras Indígenas Maró, no vale do Tapajós (Pará, na Amazônia brasileira). Descortinando sua trajetória histórica, marcada pela luta na demarcação territorial e a constante ameaça de projetos de "progresso e desenvolvimento", são produzidas reflexões que demonstram a complexidade das reações, integrando o fazer político com a força de seus saberes e fazeres.

\section{KEYWORDS}

Ethnogenesis; maró; indigenous sovereignty; Involvement

\section{PALAVRAS-CHAVE}

Etnogênese; maró; soberania indígena; envolvimento

\section{Introdução}

\footnotetext{
${ }^{22}$ Mestranda em Antropologia Social, Universidade de Brasília: barbaradiasuft@gmail.com

${ }^{23}$ Doutor em História, Universidade Federal do Norte do Tocantins: dernivaljunior@gmail.com
} 


\section{Des-envolvimentos e re-envolvimentos}

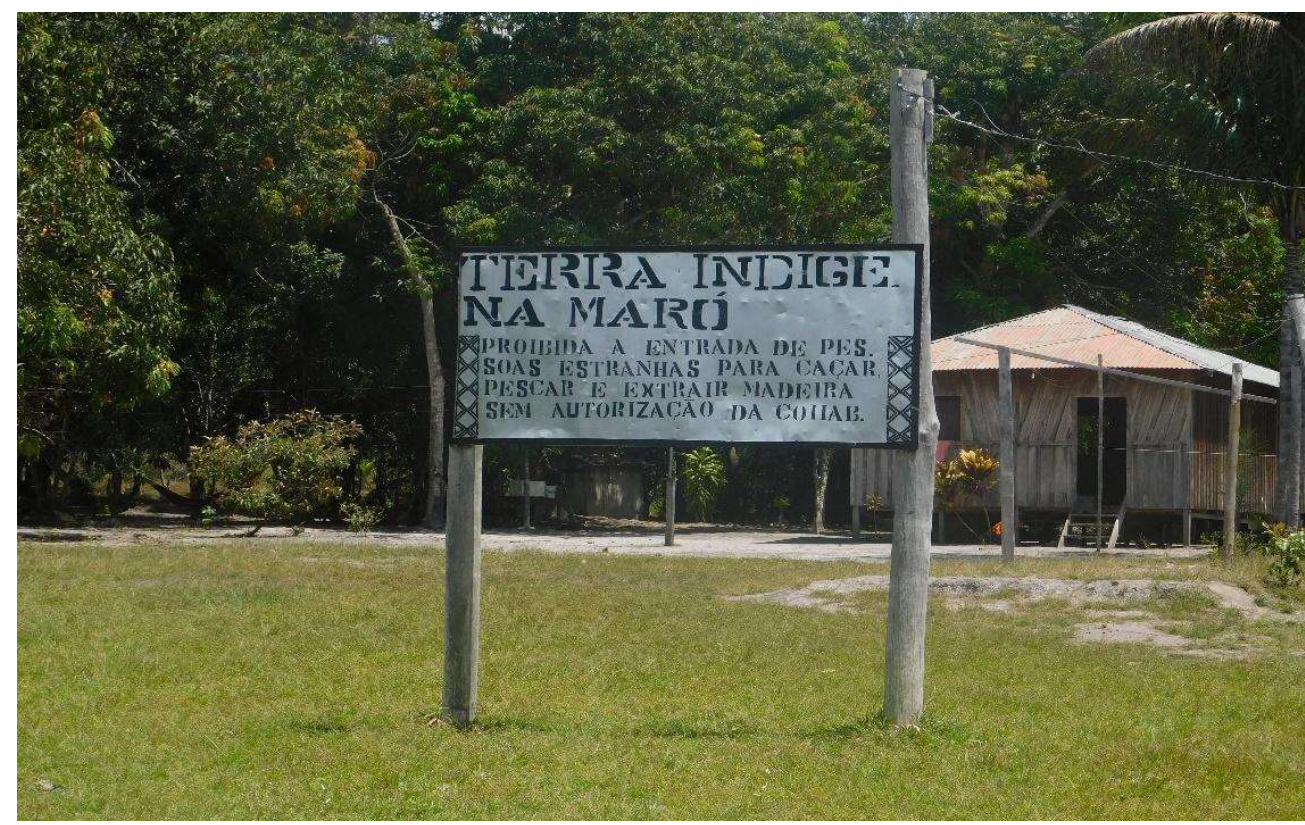

Figura 1 - Placa da autodemarcação feita pelos povos da Terra Indígena Maró. (Foto: Barbara Dias, Fev de 2017)

A região do vale do Tapajós, situada no oeste paraense, na Amazônia brasileira, apesar de marcada por violências e violações em diversos âmbitos, é reconhecida mundo afora por ser lugar símbolo de resistência contra grandes empreendimentos que atendem aos interesses do capital nacional e estrangeiro. Diversos setores tornados prioritários pela economia do Estado, como os extrativismos industrializados das mineradoras, madeireiros, exploração de recursos hídricos e a premência do agronegócio, têm entrado na disputa pelos territórios historicamente ocupados por indígenas, ribeirinhos, comunidades negras rurais e quilombolas.

O Estado tem, contraditoriamente aos princípios constitucionais, negligenciado os direitos de comunidades inteiras que têm se colocado como um impeditivo na concretização dos "projetos de desenvolvimento" (PAULA, 2013). A violência do Estado contra povos e comunidades tradicionais estrutura os ciclos de violência contra esses povos que tiveram suas histórias “escrita com o próprio sangue" (NIETZSCHE, 1983). As invasões às terras indígenas, a negação das identidades étnicas dos povos e até mesmo massacres contra essas populações vêm crescendo em números assustadores. 
Essas violações de direitos encontram legitimidade na ação do Estado e de seus agentes, e acabam por fomentar os conflitos e a violência por meio da não demarcação de Terras Indígenas e por ações racistas de não reconhecimento de etnias recentemente autodeclaradas. Exemplo disso, foi a negação do autorreconhecimento e do uso tradicional do território dos povos Borari e Arapium da Terra Indígena Maró, em decisão tomada pelo juiz federal Airton Aguiar em 2014 em Santarém, no Pará. A decisão beneficiava madeireiras que há muito vinham extraindo madeira de forma ilegal na TI e que pretendiam fazer manejo florestal naquela área. O poder político e econômico local que atuam em territórios de comunidades e povos tradicionais encontram na justiça o verniz de legitimidade de que necessitam.

Conhecida como "Arco Norte", o governo brasileiro, principalmente nos últimos governos de Lula e Dilma (2002-2016), tem intensificando investimentos para construções de um $h u b$ de infraestrutura viária, energética e industrial, dentre outros, para potencializar a rota de exportação de soja e de outros grãos produzidos no Mato Grosso pelos portos do pacífico. Dentre os projetos (des)envolvimentistas (ESCOBAR, 2005) está o complexo hidrelétrico do Tapajós, com sete grandes Usinas hidrelétricas ${ }^{24}$ e mais 143 Pequenas Centrais Hidrelétricas (PCH's), além de portos graneleiros, hidrovias, ferrovias, projetos de mineração, projetos de manejo florestal e planejamento da continuidade da pavimentação das rodovias Transamazônica e Cuiabá-Santarém. Os referidos mega-projetos, contemplados pelo Plano de Aceleração do Crescimento (Pac II) integrado ao Plano de Integração de Infraestrutura Regional Sul Americana (IIRSA), foram prioridades para os últimos governos brasileiros.

O desenvolvimento, buscado por toda a América Latina, especialmente após a Segunda Guerra Mundial, como uma extensão conectada ao capitalismo internacional da

24 A maior delas, a UHE de São Luiz do Tapajós foi arquivada em 2016 por não conseguirem elaborar o estudo de Impacto Ambiental do empreendimento que fosse satisfatório e por causa da luta dos povos do Tapajós, encabeçado pelos Munduruku e pelos beiradeiros das comunidades de Montanha e Mangabal que seriam diretamente impactadas pela barragem, onde algumas aldeias teriam que ser removidas. Remover aldeia para este fim, é proibido pela Constituição Federal brasileira. 
ideia de progresso e modernização, foi apresentado como caminho único, uma verdade inexorável da qual não podem existir outras possibilidades de resolução. $\mathrm{O}$ desafio de enfrentar todas as mazelas dos países do Sul os categoriza como subdesenvolvidos (ESCOBAR, 1995). Presente nos discursos das grandes empresas, indústrias e dos governos eleitos/usurpados na América do Sul, esse modelo de desenvolvimento pressupõe, em suma, a exploração dos chamados recursos naturais para que as sociedades cresçam a tal ponto em que todos tenham acesso à saúde, à educação e ao consumo (ESCHENHAGEN, 2015). Nomear os sujeitos naturais como recursos, já permite perceber como são inseridos em uma cadeia produtiva extrativista, impessoal porque é desenhada numa distância construída de sua manifestação.

Colocado em perspectiva histórica, é possível perceber que o atual modelo de desenvolvimento segue uma lógica extrativista que os sentidos de apropriação do período colonial, mas com a associação à modernidade e desenvolvimento. Civilização, progresso e desenvolvimento são nomes, intencional e historicamente dados, à articulação desses espaços e corpos à lógica do mercado. Os sujeitos da floresta, a vida humana animal e vegetal, são percebidos a partir de matrizes discursivas como do El dorado, a prosperidade suprema e audaciosa, a riqueza infinita e, assim, acabam por ser representadas como prêmio à exploração dos interesses daqueles que efetivamente ganham, a limitada órbita do grande capital (ESCOBAR, 2005; GROSFOGUEL, 2015).

A nova fase de exploração não se difere, assim, da feita pelo processo colonizador, entre os séculos XV e XIX. Por isso alguns autores chamam a fase atual de neoextrativismo (CARMO; CASTRO; PATRÍCIO, 2015): implica articular os recursos de determinados territórios às necessidades de matéria-prima do mercado mundial de commodities. Os direitos de povos e comunidades tradicionais e os direitos dos sujeitos naturais são, para o Estado, menores do que a referida articulação do projeto desenvolvimentista, e, por isso, essas comunidades são violentadas, violadas e até massacradas em prol dessa estrutura neo-colonizadora (CASTILHO, 2013).

Para os povos e comunidades tradicionais do "Arco Norte", esse processo tem significado uma tentativa de des-envolvê-los de seus territórios, destruir os laços que tradicionalmente os conectam aos sujeitos naturais - vegetais, animais e minerais - tendo em 
vista que a lógica de lidar, pensar e sentir com a floresta e rios, assim como suas estruturas de poder dentro da comunidade, não é a mesma do Estado moderno. E, como afirma Pierre Clastres (1979), se colocam "naturalmente" contra ele.

Transformar em mercado e mercadoria, esvaziando as relações de sentidos (seja entre sujeitos e natureza), des-envolver os povos de suas cosmologias e de seu território, são estratégias utilizadas pela colonização e têm sua continuidade, pois entendemos essa lógica a partir da ideia de colonialidade (ESCOBAR, 2005; QUIJANO, 2002). Essa estrutura de relação torna válida apenas as relações de mercado - todas as outras são inscritas como menos legítimas ou tangenciais a estas.

Como agente do projeto colonial moderno, e expressão disseminadora de sua colonialidade, o Estado reluta em reconhecer a existência de vários povos, de várias nacionalidades e de outros mundos que se posicionam além das relações geradas pelo sistema moderno/capitalista/colonial. Sua perspectiva é a da construção de um povo homogêneo e que idolatra uma nação eurocentrada, com uma única língua, em busca do mesmo sentido de vida, que atualmente se confunde com consumo, logo, sem relação profunda com os objetivos dos projetos desenvolvimentistas. Nesse projeto de nação, articulado pela colonialidade do poder, não há espaço para a pluralidade de povos, línguas, nações, estruturas de poder e de organizações - estes são percebidos como um empecilho para sua expansão e consolidação, já que se precisa que todos eles percebam a terra e a natureza como fonte de recursos a serem explorados e transformados em mercadorias.

A forma de resistência ao avanço desse projeto e seus agentes ao longo de todo o Tapajós vem se consolidando de forma autônoma e que propõe retornos/manutenção de envolvimento aos territórios, a cultura e a educação, rompendo com hegemonias do colonialismo (CASANOVA, 2002) e da colonialidade. Envolver-se no território, em suas culturas, nos saberes tradicionais se contrapõe ao des-envolvimento apregoado pelo Estado, e é resistência que se revitaliza na medida em que essas lógicas, discursos e as práticas a eles correlatos se materializam. São calamitosos para esses sujeitos.

Tomamos como inspiração de resistência o caso da Terra Indígena Maró que entre autodemarcação, retomada e utilização da educação formal como processo simultaneamente colonial e de(s)colonizador (SILVA CARVALHO; RAMOS JÚNIOR, 
2017), nos norteará nesse artigo para mostrar que as resistências e alternativas se consolidam e reflorescem no Tapajós e na Amazônia.

\section{A colonização no Baixo Tapajós}

No baixo Tapajós, onde hoje existem pelo menos 13 etnias autodeclaradas, o processo colonizador foi brutal. Com a chegada dos portugueses na segunda metade do século XVII na cidade de Santarém, conhecida a partir da política brasileira de aldeamentos do século XX como aldeia Tapajó, foram realizadas, como em todo o país, missões promovidas pelos jesuítas para catequizar os povos indígenas. Para que esse processo fosse facilitado, fizeram com que os diversos povos ali existentes falassem uma língua geral: o Nheengatu (NAVARRO, 2012). A pretensão era de torná-los povos homogeneizados e mais catequizáveis.

Com a expulsão dos Jesuítas por Marquês de Pombal, as aldeias passaram a se chamar vilas e ficaram sobre a administração do Diretório dos Índios pombalino, em 1775. De acordo com Florencio Vaz (2010), o diretório teve duração de 42 anos e foi responsável, em grande parte, pela desestruturação social dos povos indígenas. Em todo o vale do rio Amazonas, as etnias que tinham maior unidade fugiram para lugares mais distantes, para cabeceiras de outros rios da floresta. Os demais eram chamados de tapuios e tinham a mãode-obra explorada para extração da borracha e para outros interesses coloniais. De acordo com Jane Beltrão (2013), os Tapuios e os caboclos (denominação pejorativa dada pelos colonizadores) eram povos que sofreram intensamente com o processo colonizador; que não foram extintos fisicamente, mas perderam a língua nativa e lhes foram impostas, além da língua geral, valores e costumes que, até então, não significavam suas realidades.

Outro ponto importante na história do povo Borari foi a guerra da Cabanagem, conforme aponta Vaz (2010), confirmado por Adenilson Borari. Antes, os Borari habitavam essencialmente Alter do Chão, mas foram, cada vez mais, para lugares distantes e mais adentro da floresta. A Revolta uniu indígenas, brancos empobrecidos e negros contra as violências e a exploração dos portugueses e foi duramente reprimida com seus insurgentes perseguidos. De acordo com Langfur (2011), a necessidade de se fazer invisibilizado não deve ser confundida com a extinção desses povos e sim como estratégia necessária para 
sobrevivência tanto pelos processos de explorações, como pelas perseguições realizadas pela Coroa contra indígenas.

Nesse sentido, diversas estratégias de sobrevivência foram traçadas dentro de um contexto no qual o Estado tinha como princípio as seguintes lógicas de intervenção sobre povos indígenas: (1) que estes deveriam ser civilizados, catequizados, incorporados ao modo de vida europeu, a suas estruturas de poder e de pensar, adotando sua língua e religião, e que considerava o ser indígena como um estágio a ser superado na escala evolutiva da humanidade ou (2) de que esses "selvagens" deveriam ser dizimados, com suas forças de trabalho exauridas e suas terras exploradas, tendo em vista que eram, por excelência, corpos e almas inferiores.

Diante disso, não é difícil compreender que ao esconder suas etnicidades (BARTH, 2005) ou de se dispersar enquanto grupo para lugares mais distantes e menos acessíveis aos colonizadores, estavam se utilizando de uma estratégia de sobrevivência. Dentro do contexto brutal de violência ao qual estavam expostos, essa era a forma mais acessível para a manutenção dos seus modos de viver e preservação de suas próprias vidas. Não falar a língua materna em um tempo e espaço em que conversar pode justificar repressões que levam a mortes culturais e físicas de um povo, não se trata meramente de escolher a língua colonizadora, mas sim de uma imposição que é acatada - em partes - para a sobrevivência de um povo ou grupo étnico (RIVERA CUSICANQUI, 2010).

A resiliência cultural (FUENTE, 2012) é manifesta em muitas estratégias e a língua é apenas uma das formas de linguagem de um povo: sua identidade resistiu ao longo desse período. Não que isso signifique categoria de análise para identificar se determinado grupo é ou não indígena, significa apenas que costumes e tradições podem resistir até mesmo em contextos nada favoráveis para sua existência, por meio das histórias orais e da memória coletiva a qual pertencem. Quando um povo ou grupo é dispersado para diversos lugares, sem pouca ou nenhuma interação com o grupo pertencente, a memória coletiva (TOLEDO; BARRERA-BASSOLS, 2009) resiste, mas o próprio cenário dificulta a propagação cultural e a própria identidade com o grupo.

Foi na década de 1990 que diversas etnias do baixo Tapajós começaram a se autodeclarar como indígenas, num processo nomeado de etnogênese (CARVALHO, 2006; 
MAURO, 2013; MONTAGNER, 2007). O conceito explica o processo de como etnias e grupos inteiros, muitas vezes dados como extintos, reaparecem e se autodeclaram como indígenas. Esse reaparecer ou ressurgir não pode ser confundido com a invenção de ser indígena. Isso porque durante séculos esses povos tiveram que esconder e até mesmo negar suas etnicidades como estratégia de sobrevivência, mas, por meio de resistências silenciosas e discretas (VAZ, 2010), conseguiram manter muitos aspectos culturais anterior à invasão portuguesa.

"Nossa região passou por um forte processo de colonização que fez perder nossa língua. Ainda há dos nossos mais velhos os que ainda falam o nheengatu. Nós não temos a língua fluentemente, mas temos a espiritualidade”, afirma Adenilson Borari sobre a perda da língua materna. Ele ressalta um ponto importante que a colonização não conseguiu tirar de seu povo e que a colonialidade do pensar fez com que, por muito tempo, essa espiritualidade fosse praticada de forma silenciosa ou mesclada com outras religiosidades.

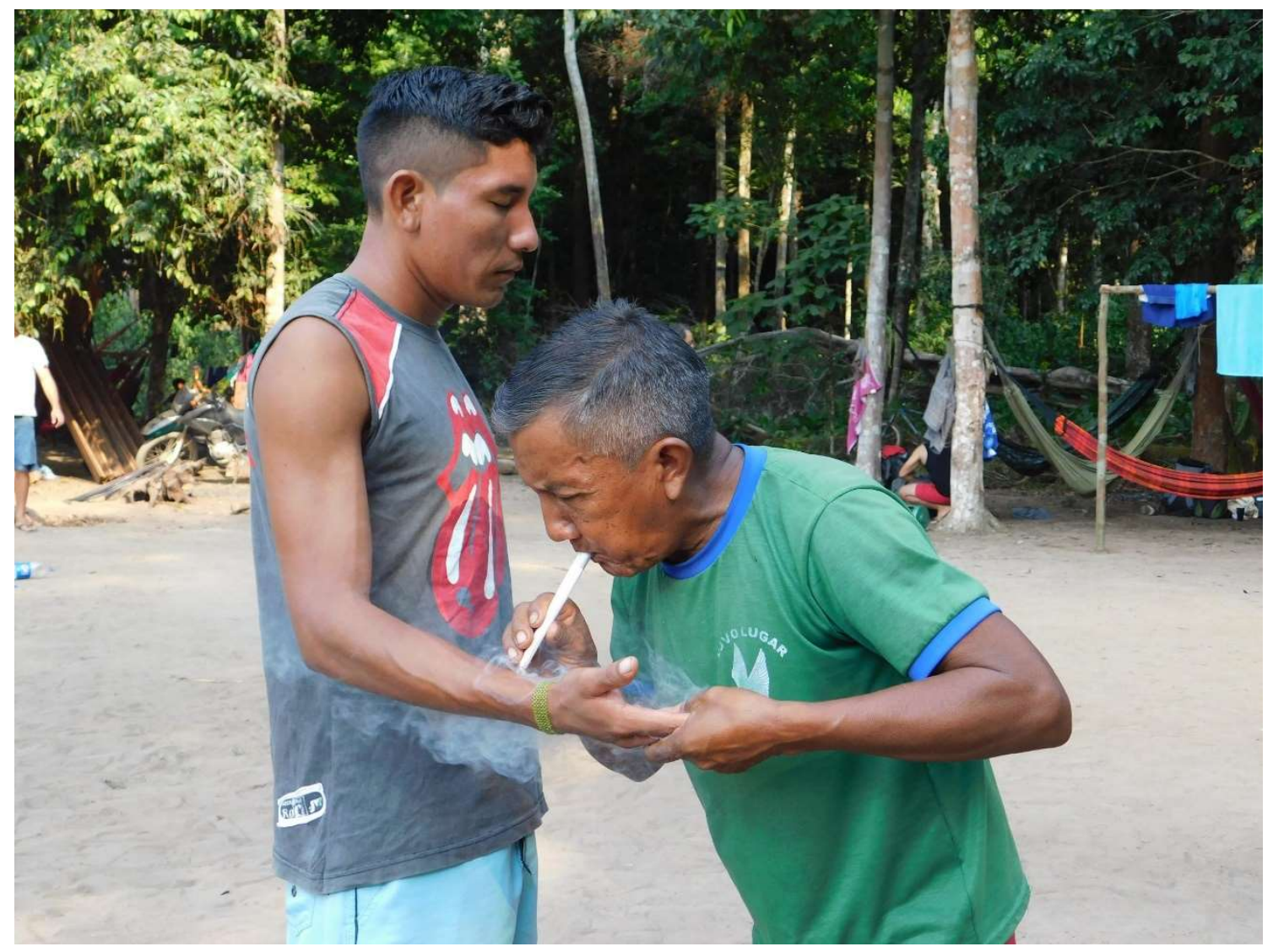

Figura 2 - Pajé Higino fazendo defumação de Tauari para que o vigilante do território possa adentrar na mata. 
O caso de reafirmação étnica dos Borari e Arapium da TI Maró, mostra como ela surge diante a necessidade de defesa de ser quem se é e do território diante dos ataques às suas etnicidades e as invasões por madeireiras e de interesses do governo. De acordo com Adenilson Borari,

A gente não tinha a necessidade de ter um território demarcado, porque o consenso na época era que tudo era nosso. Nós tínhamos a consciência de que éramos Borari, embora não tinha a necessidade de ficarmos dizendo que éramos Borari porque não tinha nada que fosse de encontro com nossos costumes e interesses [...]A partir de 2000 o movimento indígena começa emergir na TI Maró, principalmente na aldeia Novo Lugar, com discussões de como defender nosso território. Fomos fazer um estudo sobre a árvore genealógica do nosso povo, e chegou-se à conclusão que éramos Borari vindos de Alter do Chão. Naquela época decidimos que era necessário tirar um pedaço de chão para nós, porque o território já estava todo fatiado.

Essas resistências silenciosas são a força motriz para o processo de etnogênese no baixo Tapajós no final do século XX. Vale lembrar que a identidade indígena e os aspectos culturais destas não devem ser lidas como práticas estáticas no tempo que não se reinventam. Ela é plural, diversa e dinâmica como qualquer cultura.

Em muitos momentos o discurso do não "ser indígena" e ser ribeirinho, caboclo ou tapuio pode ter sido incorporada a tal ponto, delas não serem refletidas ou questionadas se era de fato uma negação ou se já nem eram mais indígenas: eram comunidades caboclas como insistia o Estado? Ribeirinhas? Poderiam deixar de ser índio? Poderiam voltar a ser?

De acordo com Manuela Carneiro da Cunha (1994), ser ou não ser índio é questão de auto-identificação de si como tal e pela comunidade ao qual o se diz pertencer. Viveiros de Castro (2006) também aponta para o mesmo entendimento, quando coloca que tampouco antropólogos têm o direito ou a autoridade de dizer quem é ou não é índio, mas tem sim, o papel de apresentar os elementos que se conectam com o que eles dizem para se reafirmar como tal. De fato, uma autoridade constituída para validar saberes usando a mesma lógica de validação de saberes ocidental pode, ao contrário, perder-se na própria colonialidade que permite seu status de existência. 
O Estado, coadunado com ruralistas e alinhado com outros interesses do capital engajadas na exploração das terras indígenas, tentam incrustar, no imaginário social, que essas comunidades, que agora se auto-afirmam indígenas são, na verdade, comunidades caboclas ou ribeirinhas, que, com o processo de colonização, perderam sua indianidade com a miscigenação. Acusa esses povos de estarem criando tradições e identidades que há muito perderam, para se aproveitar de privilégios que povos indígenas desfrutam na legislação brasileira.

De fato, esses privilégios não existem senão nos discursos de ódio proferidos contra povos indígenas para deslegitimar e desmoralizá-los diante a sociedade. O que vemos hoje é exatamente o contrário: direitos arduamente conquistados na Constituição Federal brasileira de 1988 sendo atacados, de modo que a luta dos povos indígenas segue na direção de garantir sua manutenção. Ademais, o movimento de etnogênese no baixo Tapajós se dá por meio da revitalização e valorização da cultura, dos saberes e resgate das histórias do antigos sobre lugares referências que significam suas cosmovivências.

\section{(Re)territorializações do espaço e do saber}

Assim, a relação entre povos indígenas e natureza, historicamente negligenciada pelo Estado e posta como entrave aos modelos desenvolvimentistas, vem se empoderando também nos espaços políticos e tomando corpo como forma real de resistência às lógicas do capital que matam cultural e fisicamente povos inteiros. Não perceber a natureza, ou a mãe terra, como produtos ou recursos a serem transformados em mercadoria, é o maior legado dos povos indígenas para a humanidade, que, há milênios, maneja com sabedoria e respeito florestas e rios. Essa relação que engloba diversas dimensões de ver e lidar com o mundo, podemos perceber na fala do indígena Adenilson Borari, quando mostra que o Estado tenta apagar a existência de outras relações e outras cosmovivências possíveis com aquilo que denominam de recursos naturais:

Co governo faz o que faz, para eles não importam quem vive na floresta, pra eles espíritos não existem, a floresta é apenas espaço de exploração de interesse econômico e pra gente não é assim. Nós produzimos pro nosso consumo e não pra ter estoque ou pra acumular capital. Nós não pensamos dessa forma colonizadora. 
A terra indígena Maró caminha no sentido de descolonizar os espaços e os saberes, envolvendo a comunidade, a instituição escola, pajés, lideranças e professores. $\mathrm{O}$ processo de autodemarcação, iniciada em 2007, foi uma resposta dada ao Estado diante a morosidade de iniciar o processo administrativo para a demarcação do território. Com o desencantamento em relação aos governos que se diziam a favor das lutas camponesas e indígenas, e sofrendo com as ameaças e invasões de madeireiros, as três aldeias que compõem a terra indígena perceberam que os interesses das madeireiras e do governo estavam de braços dados.

Os povos Borari e Arapium, então, decidiram fazer, eles mesmos, a demarcação física do território, a desintrusão de invasores e a vigilância e monitoramento da TI, com a formação de jovens das três aldeias para monitorar e elaborar denúncias de invasões e roubo de madeira. Com a demora do órgão estatal de elaborar estudos que comprovassem a existência da Terra Indígena, o conflito se acirrou a tal ponto de lideranças como Odair Borari ter sido sequestrado e espancado por duas vezes por madeireiros.

Apesar do processo administrativo de demarcação ter sido iniciado a partir disso e das invasões terem diminuído graças à complexa rede de estratégias elaboradas pelos dois povos para vigiar e monitorar o território, as invasões são sempre iminentes. Assim, outras estratégias de envolvimento ao território vêm sendo praticadas. A escola, uma das 

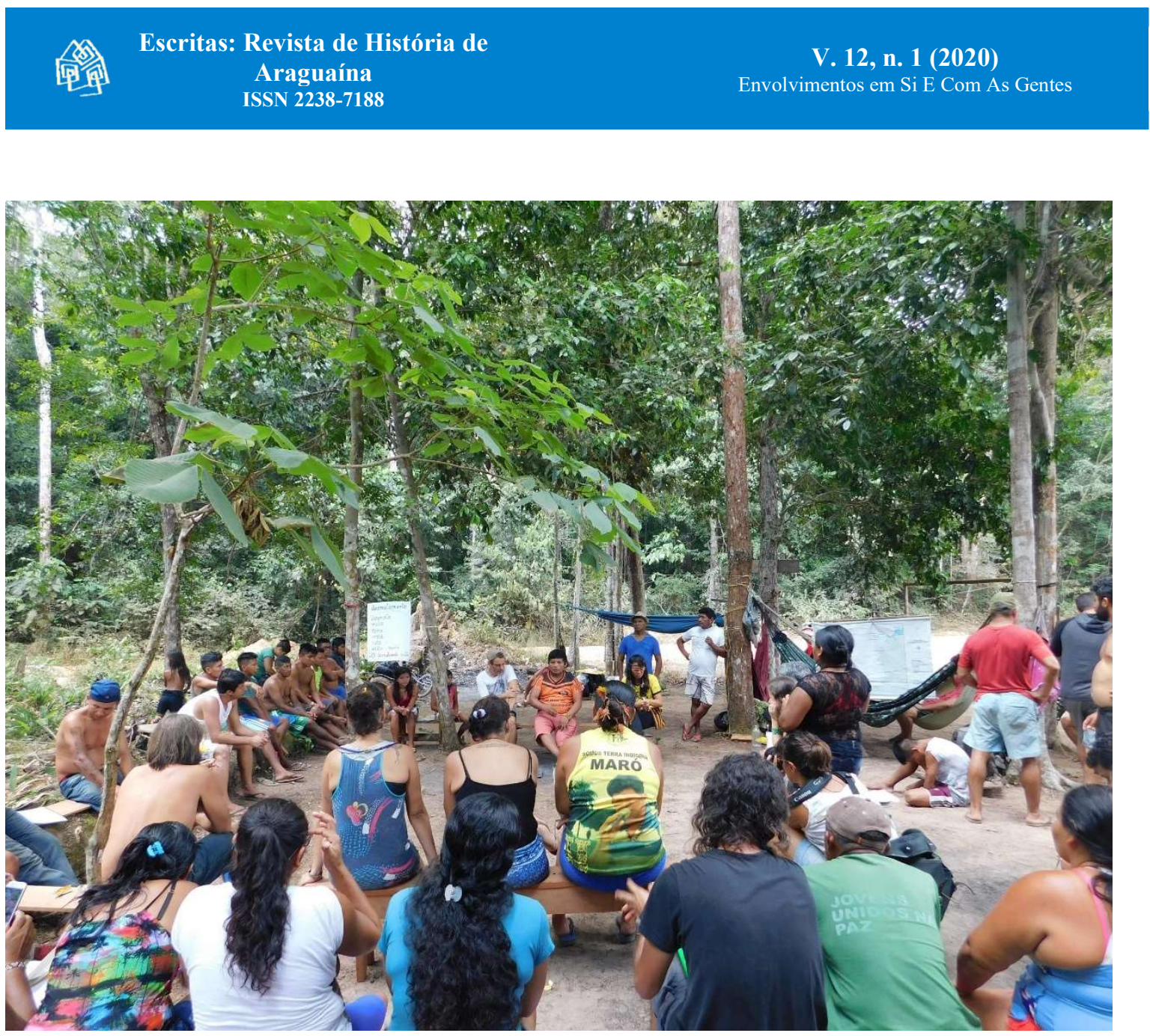

Figura 3 - Semana do 7 de setembro de 2017, caciques, pajés, guerreiros, alunos e professores indígenas na TI Maró se reuniram para trocar experiências e fortalecer saberes tradicionais no lugar onde ocorreu a retomada de casa usada por madeireiros dentro da TI. (Foto: Barbara Dias, Setembro de 2017).

principais instituições responsáveis na colonização para dominação e hoje pela colonialidade do pensar e do saber, tem sido usada para o caminho inverso: o da descolonização.

Para Adenilson Borari, se antes eles eram dominados pela estrutura da escola para negar seus saberes e conhecimentos, hoje eles se utilizam dela para recuperar e revalorizar saberes tradicionais que foram deslegitimados pela colonização e para fazer o “território indígena autônomo, independente e livre". A instituição da escola sempre teve como princípio que o saber científico e ocidental era o saber válido e legítimo, enquanto outros saberes - inclusive a filosofia indígena -, eram postos como mitos e folclore. Para os povos Borari e Arapium do Maró, a relação com o território perpassa a dimensão física.

Nossa espiritualidade está em três espaços: água, floresta e no pajé que faz a interação direta com a espiritualidade. O rio, os lagos e os igarapés têm seus espíritos, seus encantados, e a floresta também tem seus protetores. O Pajé é responsável pra fazer esse 
autocontrole com os espíritos e a natureza, já que nós convivemos e dividimos o mesmo espaço com eles. Quem vê é o pajé, e nós temos exemplos e não duvidamos disso. [...]

Isso vem se refletindo com o questionamento, inclusive, do calendário comemorativo da escola, quando chegam à conclusão que o dia comemorado pela independência do Brasil, com as escolas desfilando com bandeiras hasteadas do estadonação, o mesmo que nega suas existências, não os representam, e assim transformam a semana da pátria em semana de resistência e de envolvimento ao território e aos saberes tradicionais em lugares símbolos da resistência e da autonomia dos povos da Terra Indígena Maró.

Durante a autodemarcação, processo esse que vem acontecendo em outras Terras Indígenas ao longo do Tapajós, retomadas de pontos de apoio para madeiros foram realizadas pelas aldeias e hoje é lugar simbólico e estratégico para formações que envolvem a escola e a comunidade para proteção do território. Assim, as práticas de lideranças, caciques, pajés, educadores são voltadas para retorno e para revitalização de seus saberes, "alfabetizando as crianças pelo/para o território", trocando o monocultivo de saberes da escola tradicional pela ecologia de saberes (SANTOS, 2007; SOBREIRA; OLIVEIRA; ARGOLO, 2013) que territorializa espaços e (re)territorializa o local do saber (HAESBAERT; BRUCE, 2002).

\section{Referências}

BARTH, F. Etnicidade e o conceito de cultura. Revista antropolítica, v. 19, p. 15-30, 2005. BELTRÃO, Jane Felipe. Pertenças, territórios e fronteiras entre os povos indígenas dos rios Tapajós e Arapiuns versus o Estado brasileiro. Antares: Letras e Humanidades | vol.5, n¹0, jul-dez 2013.

CARMO, E. D. DO; CASTRO, E. M. R. DE; PATRÍCIO, J. C. DOS S. Mineração, neoextrativismo e conflitos em Barcarena. Novos Cadernos NAEA, v. 18, n. 3, p. 51-71, 2015. CARVALHO, F. A. L. Etnogênese Mbayá-Guaykur: Notas Sobre Emergência Identitária , Expansão Territorial E Resistência De Um Grupo Étnico No Vale Do Rio Paraguai (C . 16501800). Revista Fênix de História e Estudos Culturais, v. 3, n. 4, p. 1-20, 2006.

CASANOVA, P. G. Exploração, colonialismo e luta pela democracia na América Latina. Petropolis: Vozes, 2002. 
CASTILHO, N. M. Pensamento descolonial e teoria crítica dos direitos humanos na América Latina: um diálogo a partir da obra de Joaquín Herrera Flores. [s.1.] Universidade do Vale do Rio dos Sinos, 2013.

CLASTRES, P. A sociedade contra o Estado. Porto: Afrontamento, 1979.

CUNHA, M. C. DA. O futuro da questão indígena. Estudos Avançados, v. 8, n. 20, p. 121136, 1994.

DE RESENDE, A. C. Z. Direitos e autonomia indígena no Brasil (1960 - 2010): uma análise histórica à luz da teoria do sistema-mundo e do pensamento decolonial. [s.1.] Universidade de Brasília, 2014.

ESCHENHAGEN, M. L. El fracaso del desarrollo sostenible: la necesidad de buscar alternativas al desarrollo, algunas entradas. In: SERNA, A. G. et al. (Eds.). . Espaço, políticas públicas e território: reflexões a partir da América do Sul. Recife: UFPE, 2015. p. $72-102$.

ESCOBAR, A. Encountering Development: The Making and Unmaking of the Third World. Princeton: Princeton University Press, 1995.

ESCOBAR, A. O lugar da natureza e a natureza do lugar: globalização ou pósdesenvolvimento? In: A Colonialidade do Saber: Eurocentrismo e Ciências Sociais Perspectivas Latino-americanas. Buenos Aires: Colección Sur Sur, CLASCSO, 2005. p. $33-49$.

FUENTE, M. La comunalidad como base para la construcción de resiliencia social ante la crisis civilizatoria. Polis, v. 33, p. 16, 2012.

GROSFOGUEL, R. Del extractivismo económico al extractivismo epistémico y ontológico. Revista Internacional de Comunicación y Desarrollo, n. 4, p. 123-143, 2015.

HAESBAERT, R.; BRUCE, G. A desterritorialização na obra de Deleuze e Guattari. GEOgraphia, v. 4, n. 7, p. 1-15, 2002.

LANGFUR, H. Rebellion on the Amazon: The Cabanagem, Race, and Popular Culture in the North of Brazil, 1798-1840 (review). The Americas, v. 68, p. 295-296, 2011.

MAURO, V. F. Etnogênese e reelaboração da cultura entre os Krahô-Kanela e outros povos indígenas. Espaço Ameríndio, v. 7, n. jan/jun, p. 37-94, 2013.

MONTAGNER, D. Construção da etnia Náwa. Revista de Estudos e Pesquisas, FUNAI, v. 4, n. 1, p. 33-108, 2007. 
NAVARRO, E. DE A. O último refúgio da língua geral no Brasil. Estudos Avançados, v. 26, n. 76, p. 245-254, 2012.

NIETZSCHE, F. Assim falou Zaratustra: Um livro para todos e ninguém. São Paulo: Companhia das Letras, 2011.

PAULA, E. A. DE. Capitalismo verde e transgressões: Amazônia no espelho de Caliban. Dourados: UFGD, 2013.

QUIJANO, A. COLONIALIDADE, PODER, GLOBALIZAÇÃO E DEMOCRACIA. Revista Novos Rumos, n. 37, 2002.

RIVERA CUSICANQUI, S. Ch'ixinakax utxiwa: Una reflexión sobre prácticas y discursos descolonizadores. Buenos Aires: Tinta Limón, 2010.

SANTOS, B. D. S. Para além do Pensamento Abissal: das linhas globais a uma ecologia de saberes. Novos Estudos, v. 79, p. 71-94, 2007.

SILVA CARVALHO, E. S.; RAMOS JÚNIOR, D. V. Do desenvolvimento sustentável ao envolvimento integrado. Ecopedagogias como opções decoloniais. Revista Iberoamericana de Educación, v. 73, p. 35-60, 2017.

SOBREIRA, G. C.; OLIVEIRA, M. S.; ARGOLO, A. D. A. Reflexões sobre a ecologia dos saberes na prática educacional : A arte como possibilidade de emancipação. Revista SCIAS Arte/Educação, v. 1, n. 1, p. 64-77, 2013.

TOLEDO, V. M.; BARRERA-BASSOLS, N. La memoria biocultural: la importancia ecológica de las sabidurías tradicionales. Barcelona: Icaria Editorial, 2009.

VIVEIROS DE CASTRO, Eduardo. Os pronomes cosmológicos e o perspectivismo ameríndio. Mana, Rio de Janeiro, v. 2, n. 2, p. 115-144, 1996.

VAZ FILHO. F. A. A emergência étnica dos povos indígenas do baixo Rio Tapajós, Amazônia. Tese de Doutorado em Ciências Sociais - área de concentração Antropologia, Universidade Federal da Bahia, Salvador, 2010. 